\title{
Cryptic diversity in hymenolepidid tapeworms infecting humans
}

\author{
Nkouawa, Agathe
}

2015

Nkouawa, A , Haukisalmi , V , Li , T, Nakao , M , Lavikainen , A J , Chen , X, Henttonen , H

\& Ito , A 2015 , ' Cryptic diversity in hymenolepidid tapeworms infecting humans ' ,

Parasitology International , vol. 65 , no. 2 , pp. 83-86 . https://doi.org/10.1016/j.parint.2015.10.009

http://hdl.handle.net/10138/177512

https://doi.org/10.1016/j.parint.2015.10.009

publishedVersion

Downloaded from Helda, University of Helsinki institutional repository.

This is an electronic reprint of the original article.

This reprint may differ from the original in pagination and typographic detail.

Please cite the original version. 


\title{
Cryptic diversity in hymenolepidid tapeworms infecting humans
}

\author{
Agathe Nkouawa ${ }^{\mathrm{a}, 1}$, Voitto Haukisalmi ${ }^{\mathrm{b}, 1}$, Tiaoying Li $^{\mathrm{c}, 1}$, Minoru Nakao ${ }^{\mathrm{a}, *, 1}$, Antti Lavikainen ${ }^{\mathrm{d}}$, \\ Xingwang Chen ${ }^{\mathrm{c}}$, Heikki Henttonen ${ }^{\mathrm{e}}$, Akira Ito ${ }^{\mathrm{a}}$ \\ a Department of Parasitology, Asahikawa Medical University, Asahikawa, Japan \\ ${ }^{\mathrm{b}}$ Finnish Museum of Natural History Luomus, University of Helsinki, Helsinki, Finland \\ c Institute of Parasitic Diseases, Sichuan Center for Disease Control and Prevention, Chengdu, China \\ d Department of Bacteriology and Immunology/Immunobiology Program, Faculty of Medicine, University of Helsinki, Helsinki, Finland \\ e Natural Resources Institute Finland (Luke), Vantaa, Finland
}

\section{A R T I C L E I N F O}

\section{Article history:}

Received 22 July 2015

Received in revised form 25 October 2015

Accepted 28 October 2015

Available online 29 October 2015

\section{Keywords:}

Hymenolepiasis

Hymenolepis diminuta

Cryptic species complex

\begin{abstract}
A B S T R A C T
An adult hymenolepidid tapeworm was recovered from a 52-year-old Tibetan woman during a routine epidemiological survey for human taeniasis/cysticercosis in Sichuan, China. Phylogenetic analyses based on sequences of nuclear 28S ribosomal DNA and mitochondrial cytochrome $c$ oxidase subunit 1 showed that the human isolate is distinct from Hymenolepis diminuta and Hymenolepis nana, the common parasites causing human hymenolepiasis. Proglottids of the human isolate were unfortunately unsuitable for morphological identification. However, the resultant phylogeny demonstrated the human isolate to be a sister species to Hymenolepis hibernia from Apodemus mice in Eurasia. The present data clearly indicate that hymenolepidid tapeworms causing human infections are not restricted to only $H$. diminuta and H. nana.
\end{abstract}

(c) 2015 Elsevier Ireland Ltd. All rights reserved.
The family Hymenolepididae is a diverse group of tapeworms consisting of approximately 620 species in birds and 230 species in mammals, and has been assigned to many genera based on their morphological traits [1]. However, molecular phylogenetic studies on interspecific and intergeneric relationships within the family are still in their infancy [2]. Although a few members of the genus Hymenolepis sensu lato are of medical importance as pathogenic organisms, their taxonomy is still controversial, particularly that of Hymenolepis nana [2]. Rodent tapeworms of this genus generally require arthropod intermediate hosts in their life cycles. The adult tapeworms parasitize in rodent intestines, and the eggs develop into cysticercoid larvae in the hemocoel of insects, mainly beetles (Coleoptera).

Human infections with adult hymenolepidid tapeworms (hymenolepiasis) occur worldwide, particularly in tropical and subtropical countries under poor hygienic conditions. Most patients remain asymptomatic. The human hymenolepiasis has been generally believed to be caused only by the mouse tapeworm $H$. nana and the rat tapeworm Hymenolepis diminuta, of which $H$. nana is by far the most common because human-to-human infections occur frequently in children by directly ingesting the parasite eggs as a result of contamination of house dust, food and water with human feces [3]. Human infections with $H$. diminuta via beetle intermediate hosts have been found less frequently [3]. Humans seem to become infected with $H$. diminuta due to

\footnotetext{
* Corresponding author.

E-mail address: nakao@asahikawa-med.ac.jp (M. Nakao).

1 These authors contributed equally to this article.
}

the accidental ingestion of small beetles in stored cereal crops. Diagnosis of hymenolepiasis in human patients and differentiation of causative species are usually based on the morphology of eggs recovered from feces.

The taxonomy and identification of $H$. diminuta are problematic issues since the taxon includes a complex of cryptic species [2], indicating a possibility that clinical samples (i.e. proglottids and eggs) from human patients might be often misdiagnosed as $H$. diminuta. Originally, $H$. diminuta was discovered in the brown rat, Rattus norvegicus, from Europe. Several species of Eurasian field mice (Apodemus spp.) were subsequently listed as definitive hosts for $H$. diminuta [4]. However, additional descriptions of Hymenolepis apodemi [4], Hymenolepis pseudodiminuta [5] and Hymenolepis hibernia [6] from Apodemus spp. suggested that true $H$. diminuta is a specific parasite of Rattus spp. The infectivities of these newly defined Hymenolepis spp. to humans are completely unknown. We report here an unexpected and novel finding about a causative agent of hymenolepiasis in humans.

During a routine epidemiological survey for human taeniasis/cysticercosis in remote communities of Ruoergai region of Sichuan, China (located at the eastern margin of the Tibetan Plateau), hymenolepidid eggs were detected in a fecal sample from a 52-year-old Tibetan woman. She showed no clinical signs. Under approval of the local informed consent form, a deworming treatment was done for her using pumpkin seeds and areca nut extract [7]. An adult tapeworm expelled was washed with tap water and then kept in $70 \%$ ethanol for subsequent morphological observation and molecular identification. Mature eggs were obtained from the terminal gravid proglottids. Measuring the diameter of eggs, the thickness of outer coat (egg-shell), the size 
of oncospheres, and the length of embryonic hooks was done after mounting the eggs in Berlese's medium.

The human-derived hymenolepidid tapeworm was subjected to a molecular phylogenetic analysis, together with 13 reference samples ( $H$. diminuta and $H$. hibernia) from collections of the Finnish Museum of Natural History and 3 laboratory strains (H. diminuta, H. nana and Hymenolepis microstoma) kept in Asahikawa Medical University, Japan. Parasite genomic DNA was purified from a small part of proglottids using DNeasy tissue kit (QIAGEN) and then used as a template for PCR. Nuclear 28S ribosomal DNA (rDNA) and mitochondrial cytochrome $c$ oxidase subunit 1 ( $\operatorname{cox} 1)$ were selected as target genes. The 28S rDNA primers XZ-1 and 1500R [2] and the original cox1 primers Hym-cox1F (5'-GTT ACT AAT CAT GGT ATT ATT ATG-3') and Hymcox1R (5'-CCA AAA TAA TGC ATA GGA AAA-3') were used for PCR amplification and subsequent DNA sequencing. Procedures of the PCR and sequencing were the same as those reported previously [8]. The resultant sequences were submitted to BLAST homology search [http:// blast.ncbi.nlm.nih.gov] to check sequence identity. All of the sequences determined in this study have been deposited into DDBJ/EMBL/ GenBank databases (Supplementary Table 1). In the case of 28S rDNA, sequences retrieved from the databases were also added to the present analysis. Nucleotide data sets of nuclear 28S rDNA and mitochondrial cox1 were prepared using the multiple aligner MAFFT [9]. Gaps were completely removed from the alignments. The genetic software MEGA $6[10]$ was used to find nucleotide substitution models and to estimate phylogenetic trees by maximum likelihood (ML) method. Midpointrooted ML trees were generated from the data sets by 500 bootstrap repetitions under the model HKY $+\mathrm{G}$ for $28 \mathrm{~S}$ rDNA and the model TN93 + G for cox1. Pairwise divergence values were also computed at interspecific and intraspecific levels using the MEGA6.

The adult tapeworm from a Tibetan woman was approximately $10 \mathrm{~cm}$ in length and $3 \mathrm{~mm}$ in maximum width. The scolex was lost, and furthermore the contracted body in ethanol was unsuitable for morphological observation of reproductive organs in mature proglottids. As shown in Fig. 1, eggs obtained from the gravid proglottids had a spherical shape similar to those of H. hibernia, H. pseudodiminuta and $H$. apodemi. The egg size of the human tapeworm was $63 \mu \mathrm{m}$ in mean diameter $(n=12)$, overlapping with those of the above-mentioned three species [4]. The egg outer coat was relatively thick; $4.0 \mu \mathrm{m}$ in mean thickness $(\mathrm{n}=7)$. The oncosphere was oval; $28.4 \times 34.6 \mu \mathrm{m}$ in mean size $(n=10)$. The embryonic hooks were relatively long; $16.5 \mu \mathrm{m}$ in mean length $(n=7)$. These egg features appear to be similar to those of $H$. apodemi [4]. However, the lack of information about morphological features of reproductive organs prevented us to definitively identify the human tapeworm in China.

The BLAST homology search using nuclear 28S rDNA and mitochondrial cox 1 sequences demonstrated the unidentified tapeworm not to be

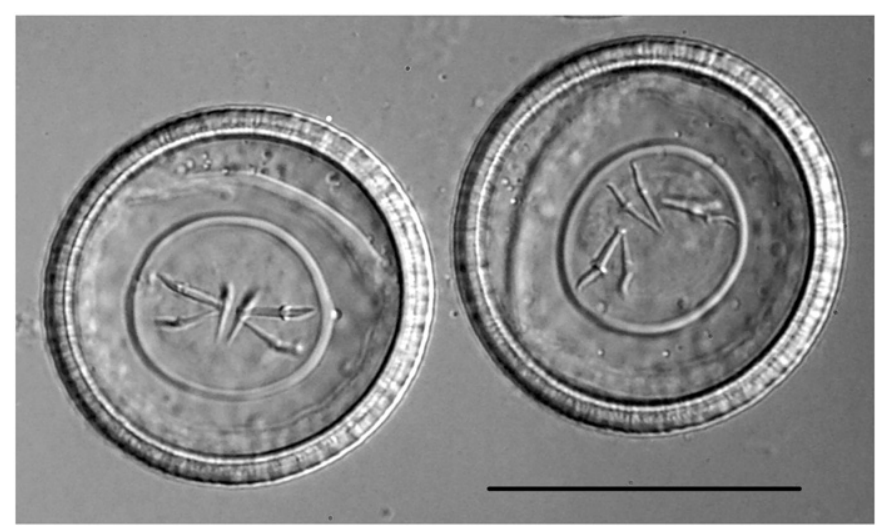

Fig. 1. Spherical eggs of a hymenolepidid tapeworm derived from a Tibetan woman in China. Scale bar represents $50 \mu \mathrm{m}$. Resolution of the microscopic photograph was enhanced using Nomarski prism. identical to any of the hymenolepidid tapeworms recorded in DNA databases. To clarify its taxonomic position, a preliminary molecular phylogeny of human-infecting hymenolepidid tapeworms was made based on DNA sequences of 28S rDNA and cox1 (Fig. 2). The data sets $28 \mathrm{~S}$ rDNA and cox 1 consisted of 1243 and 1000 nucleotide sites, respectively. Both the gene data sets resulted in a very similar phylogeny, showing that the unidentified tapeworm is distinct from the human-infecting tapeworms, $H$. diminuta and $H$. nana. The unidentified tapeworm occupied a sister position relative to $H$. hibernia. Intraspecific divergence values of variable cox1 ranged from 0.054 to 0.000 in $H$. hibernia isolates $(\mathrm{n}=11)$ and from 0.021 to 0.004 in $H$. diminuta isolates $(\mathrm{n}=3)$. Whereas, divergence values of cox 1 between the unidentified tapeworm and each isolate of $H$. hibernia ranged from 0.141 to 0.131 , suggesting that the unidentified tapeworm differs from $H$. hibernia at species level.

This report clearly demonstrates that hymenolepidid tapeworms causing human infections are not restricted to only $H$. diminuta and $H$. nana. Although the human-derived hymenolepidid tapeworm in China remained unidentified, the present molecular phylogeny showed that the human isolate is the most related to H. hibernia from Eurasian Apodemus mice. As indicated in Fig. 2, H. hibernia is widely distributed in the Palaearctic region. Recently, a new species of Hymenolepis from Apodemus peninsulae, Apodemus uralensis and Apodemus agrarius in the south of Russian Far East, western Siberia and Kazakhstan has been described as H. apodemi [4]. In the highlands of the eastern margin of the Tibetan Plateau where the unidentified tapeworm was found, the Sichuan field mouse (Apodemus latronum) and the South China field mouse (Apodemus draco) are endemic [11], together with A. peninsulae and A. agrarius from which $H$. apodemi has been found. The shared rodent fauna and the morphological similarity of parasite eggs suggest that $H$. apodemi is a potential candidate for the unidentified human tapeworm, although a possibility of a new species also should be considered. Further taxonomic studies are needed to integrate molecular and morphological data of $H$. diminuta species complex.

The Eurasian Apodemus spp. generally inhabit forests, forest edges and grasslands, and perpetuate the sylvatic life cycles of Hymenolepis spp. with arthropod intermediate hosts. As compared with Apodemus mice, house rats and house mice are more directly linked with human living environments. An early experimental study of $H$. hibernia [6] indicated that the Apodemus-derived parasite can infect rats (Rattus norvegicus) more easily than mice (Mus musculus). Another Apodemus-derived parasite, H. pseudodiminuta, also has a loose hostspecificity at the adult stage [12]. The host-switching of Hymenolepis spp. from Apodemus to Rattus has an important implication because the resultant synanthropic life cycles could be associated with human infections.

Moreover, in the cases of human infections with $H$. nana, researchers and health workers should pay attention to the possible involvement of cryptic species originating from wild rodents [13]. In Australia, H. nanalike eggs in human feces were identified as H. microstoma using a mitochondrial DNA analysis, although the adult tapeworms were not confirmed from the patients [14]. Even at the present time, the generic assignment of $H$. nana and $H$. microstoma is a problematic issue, and these species cannot be unambiguously assigned to any existing genus [2]. Based on the morphological distinctiveness of the scolex, they are sometimes classified into the genus Rodentolepis [1,2] or Vampirolepis $[15,16]$. However, the species of Rodentolepis, Vampirolepis and other hymenolepidids with rostellar hooks do not truly belong to Hymenolepis, because the members of latter genus have a rudimentary rostellum without hooks [1,2]. Therefore the generic assignment "Hymenolepis sensu lato" is preferred for H. nana and H. microstoma, and "Hymenolepis sensu stricto" should be used only for $H$. diminuta species complex. Rodentolepis-like species are morphologically similar to each other, and utilize many species of rodents as definitive hosts, including the house mice Mus musculus and Mus domesticus. A PCRbased molecular identification using clinical samples of fecal eggs and 

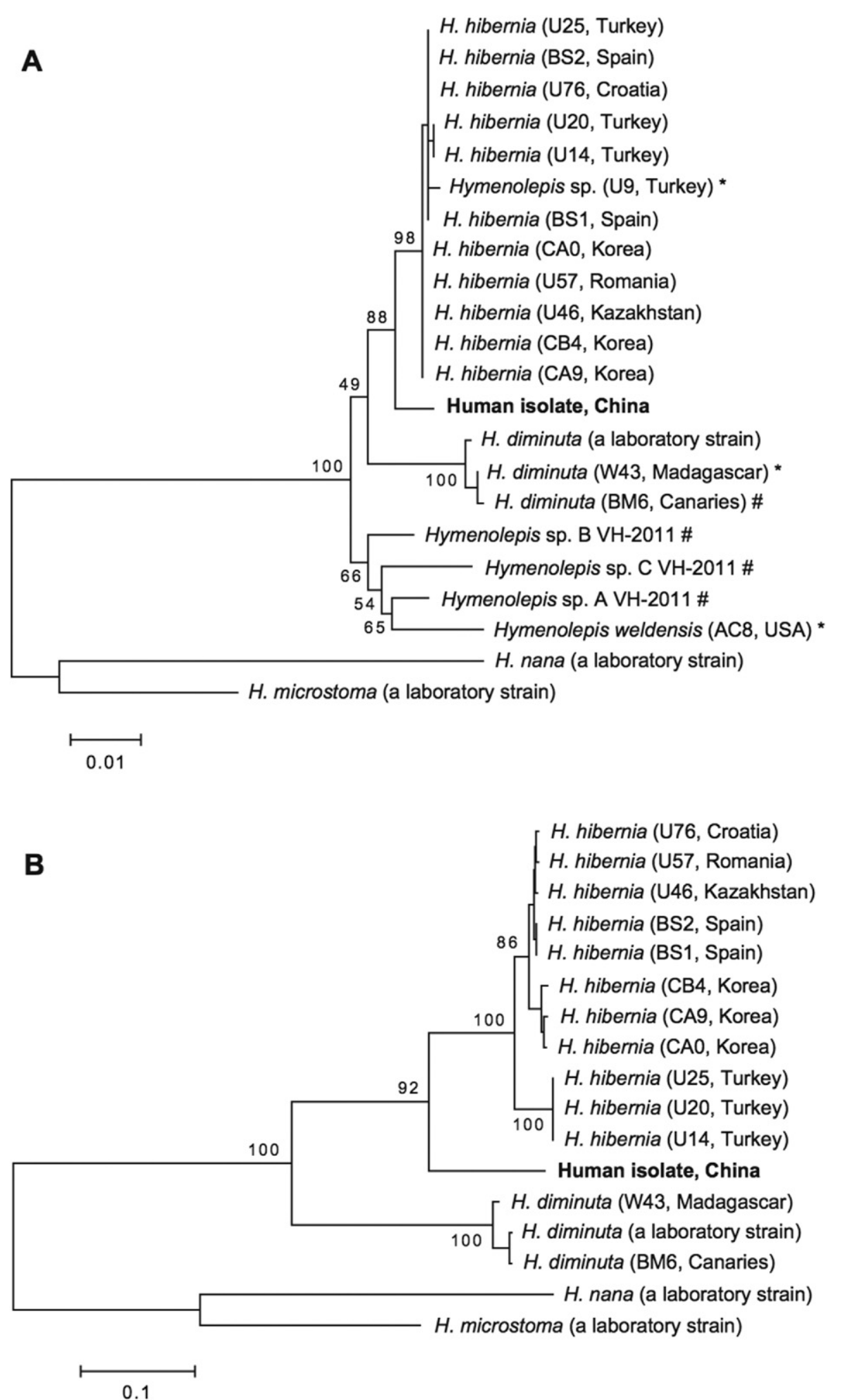

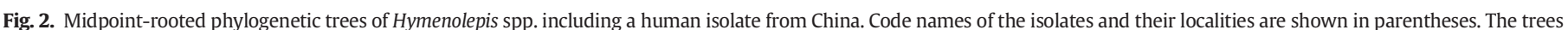

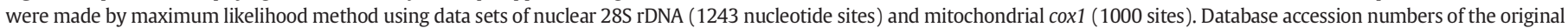

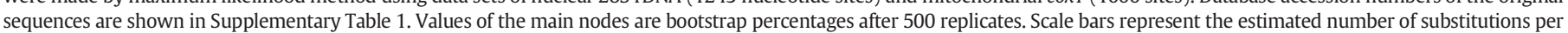

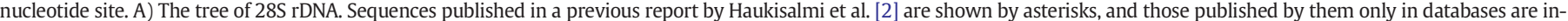
dicated with hash symbols. B) The tree of cox1.

ploglottids is necessary to clarify whether other hymenolepidid tapeworms are involved in human infections with so-called " $\mathrm{H}$. nana". A molecular phylogenetic survey using $H$. nana isolates from humans and rodents suggests a possibility that $H$. nana is a cryptic species complex containing at least two morphologically indistinguishable species [17], one of them possibly representing Hymenolepis fraterna [18]. However, the occurrence of the two cryptic species was not related to the host origins (humans and rodents). A mitochondrial DNA barcoding system 
should be prepared for hymenolepidid cestodes parasitizing humans and rodents in collaboration with tapeworm taxonomists to better understand causative species of hymenolepiasis.

Supplementary data to this article can be found online at http://dx. doi.org/10.1016/j.parint.2015.10.009.

\section{Acknowledgments}

Jukka T. Lehtonen, Carlos Feliu and Pilar Foronda are acknowledged for collecting some of the cestode specimens used in the phylogenetic analysis. Thanks are also due to Munehiro Okamoto for his early suggestions on PCR identification. This work was supported, in part, by the Japan Society for the Promotion of Science (JSPS) Postdoctoral Fellowship for Foreign Researchers (no. 26-04103) to Agathe Nkouawa under the assistance of Yasuhito Sako and by a Grant-in-Aid for Scientific Research (no. 26460503) from JSPS to Minoru Nakao.

\section{References}

[1] B. Czaplinski, C. Vaucher, Family Hymenolepididae Ariola, 1899, in: L.F. Khalil, A. Jones, R.A. Bray (Eds.), Keys to the Cestoda Parasites of Vertebrates, CAB International, Wallingford, Oxfordshire 1994, pp. 595-663.

[2] V. Haukisalmi, L.M. Hardman, P. Foronda, C. Feliu, J. Laakkonen, J. Niemimaa, et al., Systematic relationships of hymenolepidid cestodes of rodents and shrews inferred from sequences of 28S ribosomal RNA, Zool. Scr. 39 (2010) 631-641.

[3] L.S. Garcia, Intestinal cestodes, Diagnostic Medical Parasitology, fifth ed.ASM Press, Washington D.C. 2006, pp. 357-380.

[4] A.A. Makarikov, V.V. Tkach, Two new species of Hymenolepis (Cestoda: Hymenolepididae) from Spalacidae and Muridae (Rodentia) from eastern Palearctic, Acta Parasitol. 58 (2013) 37-49.

[5] F. Tenora, M. Asakawa, M. Kamiya, Hymenolepis pseudodiminuta sp. n. (Cestoda: Hymenolepididae) from Apodemus spp. (Rodentia: Muridae) in Japan, Helminthologia 31 (1994) 185-189.
[6] S.S.J. Montgomery, W.I. Montgomery, T.S. Dunn, Biochemical, physiological and morphological variation in unarmed hymenolepids (Eucestoda: Cyclophyllidea), Zool. J. Linnean Soc. 91 (1987) 293-324.

[7] T. Li, A. Ito, X. Chen, C. Long, M. Okamoto, F. Raoul, et al., Usefulness of pumpkin seeds combined with areca nut extract in community-based treatment of human taeniasis in northwest Sichuan province, China, Acta Trop. 124 (2012) 152-157.

[8] Z. Hailemariam, M. Nakao, S. Menkir, A. Lavikainen, T. Yanagida, M. Okamoto, et al., Molecular identification of unilocular hydatid cysts from domestic ungulates in Ethiopia: implications for human infections, Parasitol. Int. 61 (2012) 375-377.

[9] K. Katoh, D.M. Standley, MAFFT multiple sequence alignment software version 7: improvements in performance and usability, Mol. Biol. Evol. 30 (2013) 772-780.

[10] K. Tamura, G. Stecher, D. Peterson, A. Filipski, S. Kumar, MEGA6: molecular evolutionary genetics analysis version 6.0, Mol. Biol. Evol. 30 (2013) 2725-2729.

[11] H. Sakka, J.P. Quéré, I. Kartavtseva, M. Pavlenko, G. Chelomina, D. Atopkin, et al., Comparative phylogeography of four Apodemus species (Mammalia: Rodentia) in the Asian far east: evidence of quaternary climatic changes in their genetic structure, Biol. J. Linn. Soc. 100 (2010) 797-821.

[12] A. Ishih, T. Sekijima, M. Asakawa, F. Tenora, R. Uchikawa, Hymenolepis pseudodiminuta Tenora et al. 1994 from Apodemus speciosus and H. diminuta: a comparison of experimental infections in rats, Parasitol. Res. 89 (2003) 297-301.

[13] A. Ito, Basic and applied problems in developmental biology and immunobiology of cestode infections: Hymenolepis, Taenia and Echinococcus, Parasite Immunol. 37 (2015) 53-69.

[14] M.G. Macnish, U.M. Ryan, J.M. Behnke, R.C.A. Thompson, Detection of the rodent tapeworm Rodentolepis (=Hymenolepis) microstoma in humans. A new zoonosis? Int. J. Parasitol. 33 (2003) 1079-1085.

[15] G.D. Schmidt, CRC Handbook of Tapeworm Identification, CRC Press Inc., Boca Raton, 1986 (675 pp.).

[16] A.A. Spasskii, Klassifikaciya gimenolepidid mlekopitayuschih, Trudy Gel'mintologicheskoi Laboratorii, Akad. Nauk SSSR 7 (1954) 120-167.

[17] M.G. Macnish, U.M. Morgan-Ryan, P.T. Monis, J.M. Behnke, R.C.A. Thompson, A molecular phylogeny of nuclear and mitochondrial sequences in Hymenolepis nana (Cestoda) supports the existence of a cryptic species, Parasitology 125 (2002) 567-575.

[18] J.G. Baer, F. Tenora, Some species of Hymenolepis (Cestoidea) from rodents and from primates, Acta Sci. Nat. Brno 4 (1970) 1-32. 